\title{
FAKTOR-FAKTOR YANG BERHUBUNGAN DENGAN TINGKAT KECEMASAN PADA PASIEN PRE OPERASI BEDAH UMUM DI RUMAH SAKIT UMUM DAERAH KABUPATEN KEPULAUAN MERANTI
}

\author{
Nur Maimun dan Debby Arini
}

STIKes Hang Tuah Pekanbaru

Email: nurmaimun83@gmail.com

\begin{abstract}
Anxiety is a subjective experience of the individual and can not be observed directly as well as an emotional state without a specific object. Surgery or surgery is an action treatment using invasive way to open or display the body part being handled. Quantitative research methods with cross sectional study design with the general population of all surgical patients who will undergo surgery in hospitals district Meranti Islands in 2015 which amounted to 607 people. The result showed that there was significant relationship between traumatic events be at the level of anxiety Pvalue = 0.013 between the emotional conflicts with the level of anxiety Pvalue = 0.000 between Impaired self-concept and anxiety level Pvalue $=0.004$ between physical disorder with anxiety level Pvalue $=0.001$ and the threat of self-esteem with the level of anxiety Pvalue $=0.000$. It is recommended that the hospital more active role in providing information as well as procedures and actions to be taken so that patients who have a history of the disorder can prepare before surgery whether physical or psychological , which can provide beneficial effects for the patient .
\end{abstract}

\section{Keywords : The level of anxiety, Patient Pre surgery, General Surgery}

\section{PENDAHULUAN}

Rumah sakit adalah sebuah fasilitas, sebuah institusi dan sebuah organisasi yang fungsi utamanya adalah memberikan pelayanan kepada pasien diagnostik dan terapeutik untuk berbagai penyakit dan masalah kesehatan. Pelayanan yang ada di Rumah Sakit adalah pelayanan pengobatan baik yang bersifat bedah maupun non bedah (Aditama, 2003).

Pembedahan atau operasi adalah suatu tindakan pengobatan yang menggunakan cara invasif dengan membuka atau menampilkan bagian tubuh yang ditangani. Pasien pre operasi dapat mengalami berbagai ketakutan, takut terhadap anestasi, nyeri atau kematian, dan takut ketidaktahuan. Selain ketakutanketakutan tersebut pasien juga mengalami kekhawatiran lain seperti masalah finansial, tanggungjawab terhadap keluarga dan kewajiban pekerjaan atau ketakutan akan prognosis buruk atau kemungkinan kecacatan di masa akan datang. Hal ini memperberat ketegangan emosional yang sangat hebat yang diciptakan oleh prospek pembedahan (Baradero, 2008).

Tindakan pembedahan merupakan pengalaman yang sulit bagi hampir semua pasien. Berbagai kemungkinan buruk bisa saja terjadi yang akan membahayakan bagi pasien, tidak heran jika seringkali pasien dan keluarganya menunjukkan sikap yang agak berlebihan dengan kecemasan yang mereka alami. Kecemasan yang mereka alami biasanya terkait dengan segala macam prosedur asing yang harus dijalani pasien dan juga ancaman terhadap keselamatan jiwa akibat segala macam prosedur pembedahan dan tindakan pembiusan (Majid, dkk, 2011).

Kecemasan merupakan pengalaman subjektif dari individu dan tidak dapat diobservasi secara langsung serta merupakan suatu keadaan emosi tanpa objek spesifik. Kecemasan pada individu dapat memberikan motivasi untuk mencapai sesuatu dan merupakan sumber penting dalam usaha memelihara keseimbangan hidup.Kecemasan berbeda dengan rasa takut, rasa takut terbentuk dari proses kognitif yang melibatkan penilaian intelektual terhadap stimulus yang mengancam. Ketakutan disebabkan oleh hal yang bersifat fisik dan psikologis ketika individu dapat mengindetifikasi dan menggambarkannya (Sulistiawati, dkk, 2005).

Kecemasan dipengaruhi oleh faktor predisposisi dan faktor presipitasi. Faktor predisposisi meliputi: peristiwa traumatic, 
konflik emosional, konsep diri, frustasi, gangguan fisik, pola mekanisme koping keluarga, riwayat gangguan kecemasan, dan medikasi. Sedangkan faktor presipitasi meliputi: ancaman terhadap integritas fisik dan ancaman terhadap harga diri (Sulistiawati, dkk, 2005).

Berdasarkan survey awal wawancara non formal yang telah dilakukan oleh peneliti terhadap 10 pasien operasi bedah umum yang akan dilakukan tindakan pembedahan di ruang operasi RSUD Kabupaten Kepulauan Meranti pada tahun 2015, diperoleh bahwa pasien merasa takut/cemas bila terjadi sesuatu hal yang tidak diinginkan. Hal tersebut dapat merusak respon psikologis yang tidak menguntungkan bagi pasien yang akan menjalani operasi.

Adapun tujuan dari penelitian ini adalah mengetahui faktor-faktor yang berhubungan dengan tingkat kecemasan pada pasien pre operasi bedah umum di RSUD Kabupaten Kepulauan Meranti.

\section{METODOLOGI PENELITIAN}

Jenis penelitian ini adalah kuantitatif dengan desain penelitian Cross Sectional. Jumlah sampel dalam penelitian ini sebanyak 100 Responden dengan tekhnik sampling accidental sampling. Data yang dikumpulkan selanjutnya dilakukan pengolahan melalui tahap sebagai berikut: Pemeriksaan kembali (editing), Pengkodean (koding), Proses/entri data (Proccessing), Pembersihan data (Cleaning), Faktor-faktor yang berhubungan dengan tingkat kecemasan pada pasien pre operasi Bedah umum di RSUD Kabupaten Kepulauan Meranti menggunakan analisis statistic uji chi-square pada tingkat kemaknaan $95 \%$ atau $(\alpha=0,05)$,

\section{HASIL DAN PEMBAHASAN}

\section{Analisis Univariat}

\section{Tabel 8}

Distribusi Frekuensi Karakteristik Pasien

Berdasarkan Variabel Tingkat Kecemasan

Pasien Pre Operasi di Rumah Sakit Umum

Daerah Kabupaten Kepulauan Meranti Tahun

\begin{tabular}{|c|c|c|c|}
\hline No & Variabel & $\mathbf{N}$ & $\%$ \\
\hline \multirow[t]{5}{*}{1.} & Peristiwa & & \\
\hline & Traumatic & 67 & $67.0 \%$ \\
\hline & a. Trauma & 33 & $33.0 \%$ \\
\hline & b. Tidak Trauma & & \\
\hline & Total & 100 & $100 \%$ \\
\hline \multirow{7}{*}{2.} & Konflik & & \\
\hline & Emosional & 61 & $61.0 \%$ \\
\hline & a. Ada Konflik & 39 & $39.0 \%$ \\
\hline & Emosional & & \\
\hline & b. Tidak Ada & & \\
\hline & $\begin{array}{l}\text { Konflik } \\
\text { emosional }\end{array}$ & & \\
\hline & Total & 100 & $100 \%$ \\
\hline \multirow[t]{5}{*}{3.} & Gangguan Konsep & 30 & $690 \%$ \\
\hline & a. Ada Gangguan & 70 & $41.0 \%$ \\
\hline & Konsep Diri & & \\
\hline & b. Tidak ada & & \\
\hline & Gangguan & & \\
\hline & Total & 100 & $100 \%$ \\
\hline
\end{tabular}

4. Gangguan Fisik

a. Ada Gangguan $59 \quad 59.0 \%$

Fisik $\quad 41 \quad 41.0 \%$

b. Tidak ada gangguan

Fisik

\begin{tabular}{|c|c|c|}
\hline Total & 100 & $100 \%$ \\
\hline 5. Ancaman Harga & & \\
\hline Diri & 59 & $59.0 \%$ \\
\hline $\begin{array}{l}\text { a. Ada Ancaman } \\
\text { b. Tidak ada } \\
\text { Ancaman }\end{array}$ & 41 & $41.0 \%$ \\
\hline Total & 100 & $100 \%$ \\
\hline
\end{tabular}

6. Tingkat

$\begin{array}{lll}\text { Kecemasan } & 72 & 72.0 \%\end{array}$

a. Cemas $28 \quad 28.0 \%$

b. Tidak Cemas

$\begin{array}{lll}\text { Total } & 100 & 100 \%\end{array}$

\section{Analisis Bivariat}

a. Hubungan antara Peristiwa Traumatic dengan Tingkat Kecemasan

Tabel 9

Hubungan Antara Peristiwa Traumatic dengan Tingkat Kecemasan pada Pasien Pre Operasi di RSUD Kabupaten Kepulauan Meranti Tahun 2016 


\begin{tabular}{|c|c|c|c|c|c|c|c|c|}
\hline \multirow{3}{*}{$\begin{array}{l}\mathbf{N} \\
\mathbf{o}\end{array}$} & \multirow{3}{*}{$\begin{array}{l}\text { Peristi } \\
\text { wa } \\
\text { Traum } \\
\text { atic }\end{array}$} & \multicolumn{4}{|c|}{$\begin{array}{c}\text { Tingkat } \\
\text { Kecemasan }\end{array}$} & & & \multirow{3}{*}{$\begin{array}{c}\text { P } \\
\text { Val } \\
\text { ue }\end{array}$} \\
\hline & & \multicolumn{2}{|c|}{ Cemas } & \multicolumn{2}{|c|}{$\begin{array}{c}\text { Tidak } \\
\text { Cemas }\end{array}$} & \multicolumn{2}{|c|}{$\begin{array}{c}\text { Jumla } \\
\text { h }\end{array}$} & \\
\hline & & $\mathbf{n}$ & $\%$ & $\mathrm{n}$ & $\%$ & $\mathbf{N}$ & $\%$ & \\
\hline \multirow[t]{2}{*}{1.} & Traum & 5 & 80 & 1 & 19 & 67 & 10 & 0,0 \\
\hline & atic & 4 & .6 & 3 & .4 & & 0 & 13 \\
\hline \multirow[t]{2}{*}{2.} & Tidak & 1 & 54 & 1 & 45 & 33 & 10 & \\
\hline & $\begin{array}{l}\text { Traum } \\
\text { atic }\end{array}$ & 8 & .5 & 5 & .5 & & 0 & \\
\hline \multirow{2}{*}{\multicolumn{2}{|c|}{ Jumlah }} & 7 & 72 & 2 & 28 & 10 & 10 & \\
\hline & & 2 & .0 & 8 & .0 & 0 & 0 & \\
\hline
\end{tabular}

Hasil Penelitian menunjukkan bahwa, ada hubungan antara Peristiwa Traumatic dengan Tingkat Kecemasan pada pasien pre operasi. Dari 100 pasien, kecemasan terbanyak terjadi pada pasien yang mengalami peristiwa Traumatic, yaitu sebanyak 54 (80.6\%) sedangkan pada pasien yang tidak mengalami peristiwa traumatic sebanyak $18(54.5 \%)$.

Pada Penelitian ini diperoleh nilai Odds Ratio $(\mathrm{OR})=3,46$, yang artinya pasien yang mengalami peristiwa traumatic berpeluang 3,46 Kali mengalami cemas pada saat pre operasi dibandingkan dengan pasien yang tidak mengalami peristiwa Traumatic. Berdasarkan hasil analisa hubungan menunjukkan adanya hubungan antara Peristiwa Traumatic dengan tingkat kecemasan pasien pre operasi, dengan nilai $\mathrm{P}$ value $=0,013(\mathrm{P}<0,05)$.

(Menurut Lemone, dkk

menyatakan bahwa, Trauma dikaitkan dengan istilah kecelakaan, kecelakaan berarti cedera yang terjadi tanpa maksud, dampak kejadian yang tidak disangka-sangka. Dan perlu diketahui trauma membunuh banyak individu antara usia 1- 44 Tahun disbanding penyakit atau sakit yang lain. Trauma terjadi akibat pertukaran energi yang abnormal antara pejamu dan mekanisme dalam lingkungan predisposisi. Trauma biasanya terjadi secar mendadak, memberikan sedikit waktu bagi pasien dan keluarga untuk menyiapkan konsekuensinya. Trauma juga dapat mengubah kehidupan pasien yang sebelumnya, secara potensial mempengaruhi kemandirian, mobilitas, pemikiran kognitif dan penampilan.

\section{KESIMPULAN DAN SARAN}

\subsection{Kesimpulan}

1. Adanya hubungan yang bermakna antara Peristiwa Traumatic dengan tingkat kecemasan pasien pre operasi dengan $\mathrm{P}$ value $=0,013(\mathrm{P}<0,05)$.

2. Adanya hubungan yang bermakna antara konflik emosional dengan tingkat kecemasan pasien pre operasi dengan $\mathrm{P}$ value $=0,000(\mathrm{P}<0,05)$.

3. Adanya hubungan yang bermakna antara gangguan konsep diri dengan tingkat kecemasan pasien pre operasi dengan $\mathrm{P}$ value $=0,004(\mathrm{P}<0,05)$.

4. Adanya hubungan yang bermakna antara gangguan fisik dengan tingkat kecemasan pasien pre operasi dengan $\mathrm{P}$ value $=0,001$ $(\mathrm{P}<0,05)$.

5. Adanya hubungan yang bermakna antara ancaman harga diri dengan tingkat kecemasan pasien pre operasi dengan $P$ value $=0,000(\mathrm{P}<0,05)$.

4.2. Saran

1. Memberikan pendekatan kepada pasien Pre Operasi seperti pembacaan do'a (Kerohanian) dan ceramah agar pasien merasa lebih tenang dan tidak panik dalam menjalankan operasi.

2. Diharapkan kepada pihak Rumah Sakit Umum Daerah Kabupaten Kepulauan Meranti, agar dapat berperan aktif dalam memberikan informasi prosedur dan tindakan pre operasi kepada pasien.

3. Diharapkan kepada peneliti selanjutnya agar Diharapkan dapat lebih meningkatkan kualitas penelitian selanjutnya dengan menutupi kelemahan yang ada pada penelitian ini. Caranya dengan melakukan variasi alat ukur penelitian seperti wawancara, variable dan metode penelitian yang berbeda, sehingga kesimpulan yang diperoleh lebih menyeluruh dan komprehensif.

\section{DAFTAR PUSTAKA}

Aditama, Y, T (2010). Manajemen administrasi rumah sakit. Jakarta : UI-Press. 
Baradero, M. dkk (2008). Prinsip \& praktik Keperawatan Perioperatif. Jakarta : EGC.

Brunner \& Suddarth (2002), Buku ajar keperawatan Medikal Bedah.Jakarta :EGC.

Carpenito, L, J (2000). Faktor-Faktor yang berhubungan dengan tingkat kecemasan pada pasien pre operasi di RSUD Kota Dumai. Disertasi Tidak Diterbitkan. Program Studi Ilmu Kesehatan Masyarakat StiKes Hangtuah Pekanbaru, Pekanbaru.

Dalami,dkk (2014). Asuhan Keperawatan dengan masalah Psikososial. Jakarta Timur : CV.Trans Info Media.

Dermawan dan Rusdi (2013). Konsep dan kerangka kerja Asuhan Keperawatan Jiwa. Yogyakarta : Gosyen Publishing.

Kusumawati, F \& Hartono, Y (2011). Buku ajar keperawatan Jiwa. Jakarta : Salemba Medika.

Lemone,dkk (2012). Buku Ajar Keperawatan Medikal Bedah. Jakarta : EGC.

Lukaningsih, Z, L \& Bandiyah, S (2011). Psikologi Kesehatan. Yogyakarta : Nuha Medika.

Majid, A. dkk (2011). Keperawatan Perioperatif. Yogyakarta : Gosyen Publishing.

Notoatmojo, S. (2005). Metodologi Penelitian Kesehatan. Jakarta : Rineka Cipta.
Notoatmojo, S. (2010). Metodologi Penelitian Kesehatan. Jakarta : Rineka Cipta.

Rumah Sakit Umum Daerah Kabupaten Kepulauan Meranti, (2015). Profil RSUD Kabupaten Kepulauan Meranti.

Saam dan Wahyuni (2014). Psikologi Keperawatan. Jakarta : Rajawali Pers.

Stuart \& Sundeen (1998). Faktor-Faktor yang berhubungan dengan tingkat kecemasan pada pasien pre operasi di RSUD Kota Dumai. Disertasi Tidak Diterbitkan. Program Studi Ilmu Kesehatan Masyarakat StiKes Hangtuah Pekanbaru, Pekanbaru.

Suliswati. dkk (2005). Konsep Dasar Keperawatan Kesehatan Jiwa. Jakarta : EGC.

Undang-Undang RI no 44 tahun (2009). Tentang Rumah Sakit

Yusuf,dkk (2015). Buku Ajar Keperawatan Kesehatan Jiwa. Jakarta : Salemba Medika.

Zamriati,dkk (2013). Faktor-faktor yang berhubungan dengan tingkat kecemasan Ibu Hamil Trimester III Menjelang Persalinan di wilayah kerja Puskesmas Tuminting di wilayah Tuminting kota Manado. ejournal keperawatan (e-Kp) Volume. 1 Nomor. 1 Agustus 2013 Manado. 